\title{
Molecular identification and in vitro interaction of molds associated with dry rot of potato (Solanum tuberosum L.) collected in La Trinidad, Benguet, Philippines
}

\author{
Carreon GAD, Gandalera EE and Waing KGD
}

\begin{abstract}
Department of Biological Sciences, College of Science, Central Luzon State University, Science City of Muñoz, Nueva Ecija, Philippines 3120
\end{abstract}

Carreon GAD, Gandalera EE, Waing KGD 2021 - Molecular identification and in vitro interaction of molds associated with dry rot of potato (Solanum tuberosum L.) collected in La Trinidad, Benguet, Philippines. Studies in Fungi 6(1), 315-326, Doi 10.5943/sif/6/1/22

\begin{abstract}
Solanum tuberosum L. from the Solanaceae family is one of the most important agricultural crops grown in the Philippines next to rice. Unfortunately, harvested potatoes were plagued with various fungal diseases resulting to occurrence of dry rot affecting the production and harvest of potatoes. Dry rot in potatoes is caused by several fungal species in the genus Fusarium. Hence, this study aimed to isolate and identify fungal species associated with dry rot disease of potato. Potatoes showing diseased symptoms of dry rot were randomly selected and collected from various traders in La Trinidad, Benguet and were subjected for fungal isolation through serial dilution and plating. Identification was done through observation of cultural and morphological characteristics as well as DNA barcoding using ITS region. A total of six fungal species were subjected into BLAST which revealed the following species: Aspergillus flavus (100.00\%), A. fumigatus (100.00\%), A. niger (99.82\%), Fusarium oxysporum (95.06\%), F. solani (100.00\%) and Mucor velutinosus (96.45\%). To establish possible fungal species as potential biocontrol agent that would lessen the use of harmful chemicals, the identified fungal organisms were interacted with one another through in vitro interaction. Results showed that fungi exhibited antagonistic interaction against each other. Hyphal denaturation, hyphal penetration, hyphal coiling and cell lysis, were observed through microscopic observation. Meanwhile, M. velutinosus showed the ability to penetrate the host hyphae of the $F$. solani and $F$. oxysporum. Therefore, Mucor velutinosus could be a potential biological control agent against Fusarium species, which can reduce the use of harmful fungicides in controlling fungal diseases in potato that causes dry rot.
\end{abstract}

Keywords - antagonism - fungal diseases - hyphal interaction - Mucor velutinosus

\section{Introduction}

Potato (Solanum tuberosum L.), locally known as "patatas" is widely cultivated in 130 countries worldwide including the Philippines. According to Fernald (1970) and Spooner \& Knapp (2013), Solanum species comprise more than 1000 species. Potato follows rice and wheat as one of the most important food crop for human consumption. The nutritional composition of potato has major impacts on population health such as the presence of vitamins and minerals thereby preventing malnutrition and slows down the accumulation of chronic diseases because of its antioxidant content (Camire et al. 2009). 
However, this staple food can be infected by post-harvest diseases caused by fungi such as dry rot, caused by several species of Fusarium causing great loss in crop production. Accordance to the earlier reports, there are 13 Fusarium species considered as causal agents of dry rot of potatoes worldwide (Cullen et al. 2005) and the most frequent and devastating are $F$. sambucinum, $F$. solani and F. oxysporum (Li 1992, Ye \& Wang 1994, Peng \& Zhu 2008, Hay et al. 2018). Infection starts when the pathogen enters the tuber, causing rotting out of the center, and once the pathogens penetrated the tuber skin, it begins to develop internally into the tissue (Wharton et al. 2007).

To control fungal diseases, chemical fungicides are extensively used in agriculture but can cause problems such as environmental pollution and deterioration of human health (Gomathi \& Ambikapathy 2011). Consequently, studies reveal that a fungi can be used as a biocontrol agent if interactions between other fungi can be determined (Duffy et al. 2003). Moreover, biological control agents have specific advantages over synthetic fungicides. It was proven to have effective control of pathogens and reduces pests with the use of natural enemies (Brimmer \& Boland 2003, Adebola \& Amadi 2010). Hence, the present study was conducted to isolate and identify molds associated with dry rot of potato. Interactions between the identified molds were carried out to determine the species of fungi that have potential as bio control agent.

\section{Materials \& methods}

\section{Collection of infected potato with dry rot disease}

Potato tubers showing diseased symptoms such as dark depressions on the surface, wrinkled skin in concentric rings, necrotic areas from light to dark brown or black in color and rotted cavities (Wharton 2015) were randomly selected and obtained from 5 traders of La Trinidad, Benguet Vegetable Trading Post. Tubers were kept in proper labeled paper bags and immediately transported to laboratory for isolation.

\section{Isolation of fungal species}

Collected potato tubers were rinsed with tap water to remove the dust and adhering debris. Then, the infected part of the sample was cut from the healthy part using sterilized blades under aseptic conditions. Infected part were then rinsed with sterile distilled water for 1 minute. Then, infected potato parts were then pulverized using a blender. Ten grams from the pulverized sample were added with $90 \mathrm{ml}$ sterilized distilled water and was regarded as $10^{-1}$. Six test tubes were prepared having $9 \mathrm{ml}$ of sterilized distilled water each and were labeled from $10^{-2}$ to $10^{-7}$. One $\mathrm{ml}$ from $10^{-1}$ dilution was transferred into $10^{-2}$ dilution and was shaken. Then, one $\mathrm{ml}$ from $10^{-2}$ was transferred to $10^{-3}$ dilution. This procedure was done in which one $\mathrm{ml}$ was being transferred from one dilution to another up to $10^{-7}$ dilution. Then, one ml of sample from $10^{-1}, 10^{-3}, 10^{-5}$ and $10^{-7}$ were poured on sterilized petri plate separately and pour plated with approximately $20 \mathrm{ml}$ previously sterilized Potato Dextrose Agar (PDA). Triplicate was made for each plates. It was incubated at room temperature in alternating light and dark conditions for 4-5 days or until sufficient mycelial growth was available for isolation.

\section{Purification of fungal isolates}

Distinct fungal colonies were purified into pure culture using three-point inoculation technique. Using a sterilized needle, mycelia were isolated from the mixed culture into a previously plated PDA. The plated isolates were incubated for 4-7 days at room temperature. Isolates were only considered as pure culture when colonies show consistent growth characteristics. Pure culture of the fungal isolates were deposited at the Biodiversity Conservation Laboratory, Department of Biological Sciences, College of Science, Central Luzon State University, Science City of Munoz, Nueva Ecija, Philippines, 3120. Facesoffungi numbers were registered as mentioned in Jayasiri et al. (2015).

\section{Characterization and identification of fungi}




\section{Cultural characteristics}

Three-point inoculation was done in previously prepared plated PDA to observe the cultural characteristics of the six isolates. The re-growth, size and pigmentation of fungi were observed and recorded.

\section{Morphological characteristics}

In a petri plate with moistened tissue paper, a clean glass slide was placed on top of a vshaped foil and was sterilized. Agar block approximately $1 \mathrm{~cm}$-thick was placed on the center of the slide. Fungal species were inoculated on the agar block and covered with sterilized cover slip. Inoculated slides were incubated for 3-5 days at room temperature. After incubation, morphological characteristics were observed under a compound microscope.

\section{Molecular identification through sequencing}

Seven-day old fungal isolates cultured on test tubes with PDA medium was sent to Philippine Genome Center in Quezon City, Manila for DNA extraction and sequencing following their standard procedures and protocols. In which DNA extraction was done by CTAB method using universal ITS1 (5'- TCCGTAGGTGAACCTGCGG-3') and ITS4 (5'TCCTCCGCTTATTGATATGC-3') primers with $58^{\circ} \mathrm{C}$ annealing temperature for polymerase chain reaction. Capillary sequencing was carried out on the ABI 3730xl DNA Analyzer using a 50cm 96-capillary array, POP7TM Polymer, and 3730xl Data Collection Software v3.1 and base calling was done on Sequencing Analysis Software v5.4. Trimming and assembling of sequences were done using Codon Code Aligner V8.0.2

\section{In vitro interaction of identified fungi}

Two fungi were inoculated using one-point technique at the opposite sides of the previously plated PDA and then allowed to ramify at room temperature for seven days. After incubation, colony growth was observed and their interaction was determined (Waing et al. 2015).

\section{Identification of in vitro interaction}

Interactions of fungi were described as antagonism and mutual antagonism. Fungal isolates were classified as victim or aggressor in all antagonism tested (Dix \& Webster 1995). Mutual inhibition or mutual slight inhibition is determined if there is mutual antagonism between fungi. In mutual inhibition, the fungus approached each other until almost contacted and a demarcation line of more than $2 \mathrm{~mm}$ was visible while mutual slight inhibition shows a distance of 0.1 to $2 \mathrm{~mm}$ between two fungal colonies (Fakhrunnisa et al. 2006).

\section{Interfungal parasitic relationship}

The procedure for interfungal parasitic relationship was adopted from Matroudi et al. (2009) with minor modifications, in which the slide culture technique determined the antagonistic interaction between fungal species. In a petri plate with moistened tissue paper, a clean glass slide was placed on v-shaped foil and was sterilized. The inocula of the two fungi were placed on both ends measuring $1 \mathrm{~cm}$ apart of sterilized glass slide separately. One end of the slide was coated with approximately $5.0 \mathrm{~mm}$-thick layer of PDA while the other end was kept free for handling. The inoculated slides were incubated at room temperature for 3-5 days. After incubation, presence of coil formation and penetration structures, or wall disintegration where both hyphae meet were observed microscopically.

\section{Results}

\section{Observed symptoms of potato dry rot}

A total of six species of fungi were identified from infected potato with dry rot disease. The external part of diseased potato was seen (Fig. 1A) having dark depression on the surface with large 
lesions and the skin was dry and wrinkled (Fig. 1B). The internal diseased part of the potato was observed (Fig. 1C) with mycelial clumps of varying color from white to yellow to pink.

\section{Cultural characteristics}

The cultural characteristics of isolated fungi described on the $7^{\text {th }}$ day of incubation were as follows: A. flavus colonies (Fig. 2A) formed fastidious whitish mycelium at the margin and yellow green color at the center on obverse side of the plate. Mycelium at reverse side was dirty white in appearance with light brown color at the center with a diameter of $48.80 \mathrm{~mm}$. Colonies of $A$. fumigatus (Fig. 2B) attained $58.18 \mathrm{~mm}$ in diameter. On its surface and margin, it appears blue green in color with white fluffy mycelium. Reverse side was dark blue to pinkish in appearance with light brown color at the center. The colonies of A. niger (Fig. 2C) in PDA plate produce white spreading mycelium at the margin with powdery pale yellow to black color mycelium on the center in both sides of the agar plate. Colony growth measures $51.15 \mathrm{~mm}$. The colonies of $F$. oxysporum (Fig. 2D) were peach in color with velvetly aerial mycelium. Reversed side of the plate was yellowish to orange with dark violet mycelium on its center. Colony diameter was $57.29 \mathrm{~mm}$. The colonies of $F$. solani (Fig. 2E) in obverse side of the plate were seen creamy white in appearance with cottony mycelium. Reversed side appears yellowish to pale brown mycelium, and colony diameter measures $46.87 \mathrm{~mm}$. M. velutinosus (Fig. $2 \mathrm{~F}$ ) colonies at obverse side of the plate was seen powdery gray in color and white on the center. Reverse side of PDA plate show pale yellow in the center with white concentric rings. Colony diameter was $61.48 \mathrm{~mm}$.
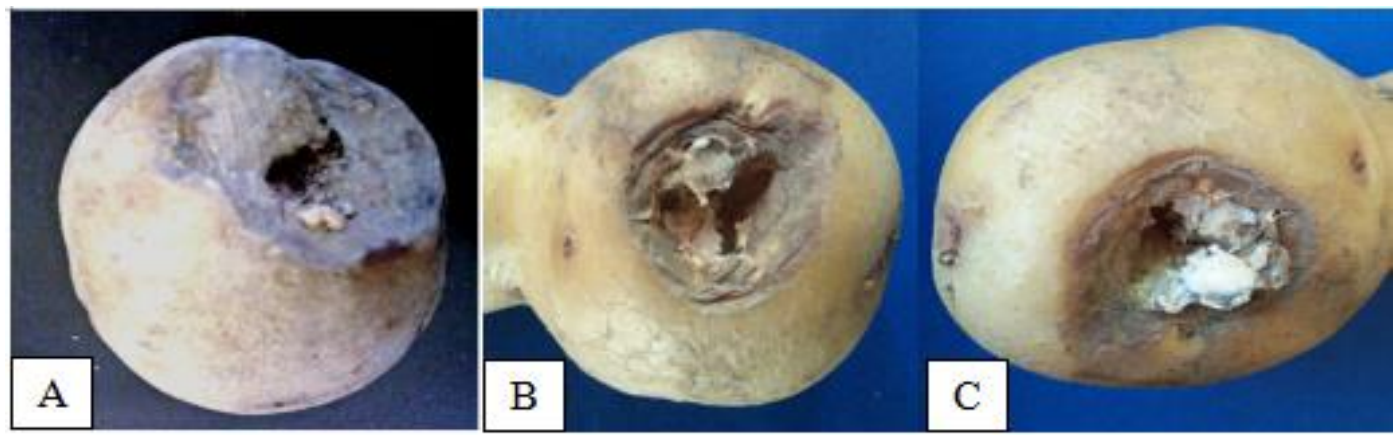

Fig. 1 - Observed symptoms of dry rot in samples collected in La Trinidad. A Benguet showing surface dark depression. B wrinkled and dry skin. C mycelial clumps in dead skin.

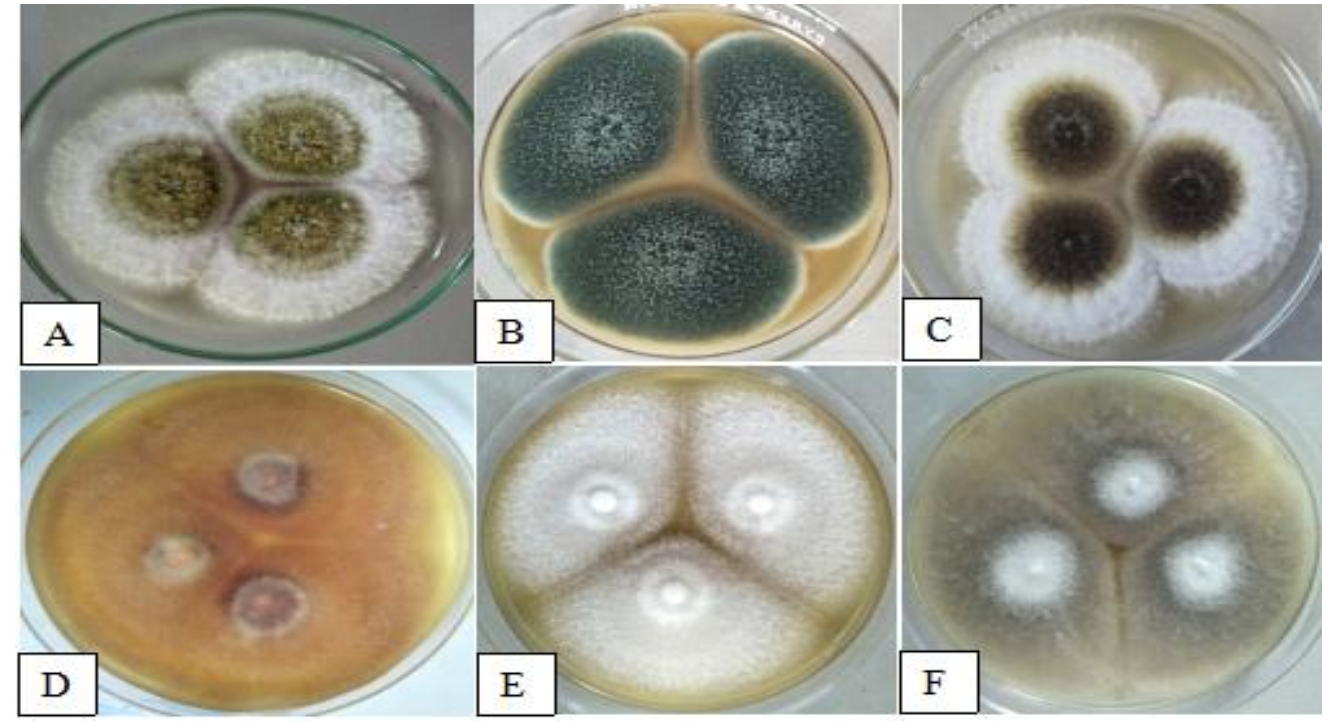

Fig. 2- Cultural characteristics represented by A A. flavus. B A. fumigatus. C A. niger. D F. oxysporum. E F. solani. F M. velutinosus. 


\section{Morphological characteristics}

Observed morphological characteristics of the isolated fungi were described on the $7^{\text {th }}$ day incubation were as follows: The stipes of A. flavus (Fig. 3A) appears rough and light brown, while the conidium was rough and have spherical surface. The conidia of A. fumigatus (Fig. 3B) is non septated and have globose shape with rough edges, conidiophores appears hyaline. Conidiophores of $A$. niger (Fig. 3C) are branched with lumped phialides. The conidiophores of F. oxysporum (Fig. 3D) were long with fusiform conidia, hypha is hyaline with branch monophialides. F. solani (Fig. 3E) shows narrow macro conidia, and long and branch monophialides. M. velutinosus (Fig. 3F) have globose sporangiospores, and formed septated hyphae.

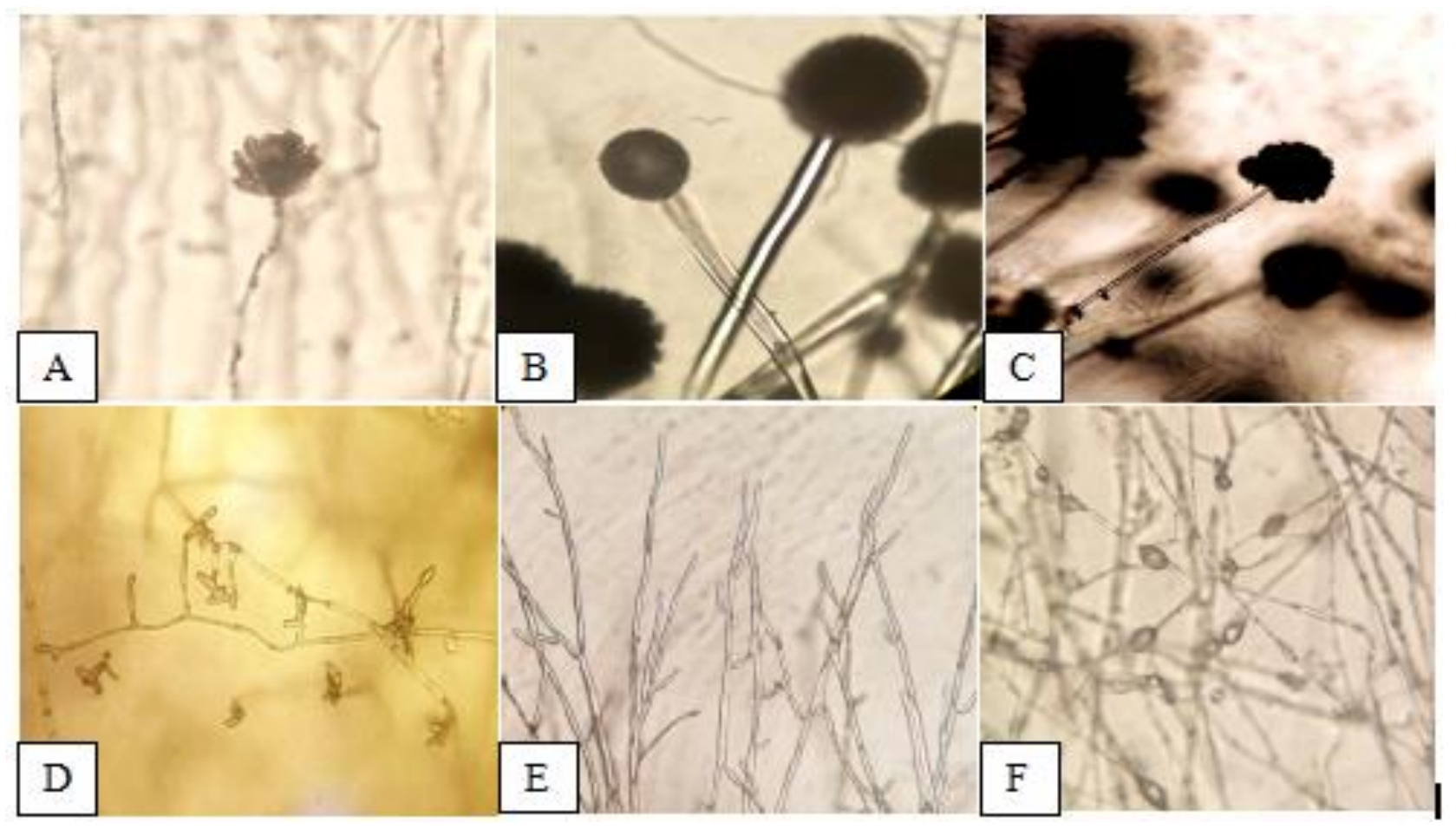

Fig. 3 - Morphological characteristics represented by A A. flavus. B A. fumigatus. C A. niger. D F. oxysporum. E F. solani. F M. velutinosus (400X).

\section{Molecular identification}

The identities of fungal organisms isolated from the $S$. tuberosum infected with dry rot disease were confirmed through amplification and sequencing of the Internal Transcribed Spacer region (ITS) region using ITS1 and ITS4 primers. BLAST analysis showed the identities of fungal isolates, namely Aspergillus flavus FoF 09597 (100\%), Aspergillus fumigatus FoF 10086 (100\%), Aspergillus niger FoF 10087 (99.82\%), Fusarium oxysporum FoF 03824 (95.06\%) Fusarium solani FoF 01873 (100\%) and Mucor velutinosus FoF 10088 (96.45\%) as shown in Table 1.

Table 1 Identities of the identified fungi with Facaesoffungi number using BLAST with NCBI Genbank Accession number.

\begin{tabular}{ccllll}
\hline $\begin{array}{l}\text { Isolate } \\
\text { No. }\end{array}$ & $\begin{array}{l}\text { FacesofFungi } \\
\text { Number }\end{array}$ & Species & E-Value & Identify & Accession \\
\hline 1 & FoF 09597 & Aspergillus flavus & 0.0 & $100.00 \%$ & MN511747.1 \\
2 & FoF 10086 & Aspergillus fumigatus & 0.0 & $100.00 \%$ & MF540309.1 \\
3 & FoF 10087 & Aspergillus niger & 0.0 & $99.82 \%$ & KY607770.1 \\
4 & FoF 03824 & Fusarium oxysporum & 0.0 & $95.06 \%$ & MG372014.1 \\
5 & FoF 01873 & Fusarium solani & 0.0 & $100.00 \%$ & MN202790.1 \\
6 & FoF 10088 & Mucor velutinosus & 0.0 & $96.45 \%$ & KY203942.1 \\
\hline
\end{tabular}




\section{Antagonistic interaction and interfungal parasitic relationship}

Meanwhile, antagonistic interaction was observed in all fungal isolates (Table 2). Antagonism in all fungal isolates was identified as aggressor or victim. The observed interfungal parasitic relationships were hyphal penetration, hyphal coiling, hyphal denaturation, hyphal branching and lysed cells, all observed under the compound microscope (Figs 4-7) (Waing et al. 2015).

Table 2 Antagonistic interaction of isolated fungi in potato tuber infected with dry rot disease.

\begin{tabular}{|c|c|c|}
\hline Interacting Fungi & & Interaction \\
\hline M. velutinosus(+) & A. flavus(-) & Antagonism \\
\hline M. velutinosus $(+)$ & A. fumigatus(-) & Antagonism \\
\hline M. velutinosus $(+)$ & F. solani(-) & Antagonism \\
\hline M. velutinosus $(+)$ & F. oxysporum(-) & Antagonism \\
\hline M. velutinosus(-) & A. niger(+) & Antagonism \\
\hline A. flavus(-) & A. fumigatus(+) & Antagonism \\
\hline A. flavus $(+)$ & F. solani(-) & Antagonism \\
\hline A. flavus(-) & F. oxysporum (+) & Antagonism \\
\hline A. flavus(-) & A. niger $(+)$ & Antagonism \\
\hline A. fumigatus(-) & F. solani $(+)$ & Antagonism \\
\hline A. fumigatus(-) & F. oxysporum $(+)$ & Antagonism \\
\hline A. fumigatus(-) & A. niger $(+)$ & Antagonism \\
\hline F. solani(-) & F. oxysporum $(+)$ & Antagonism \\
\hline F. solani(-) & A. niger(-) & Antagonism \\
\hline F. oxysporum & F. oxysporum & Antagonism \\
\hline F. oxysporum $(+)$ & A. niger(-) & Antagonism \\
\hline
\end{tabular}

(+) aggressor, (-) victim

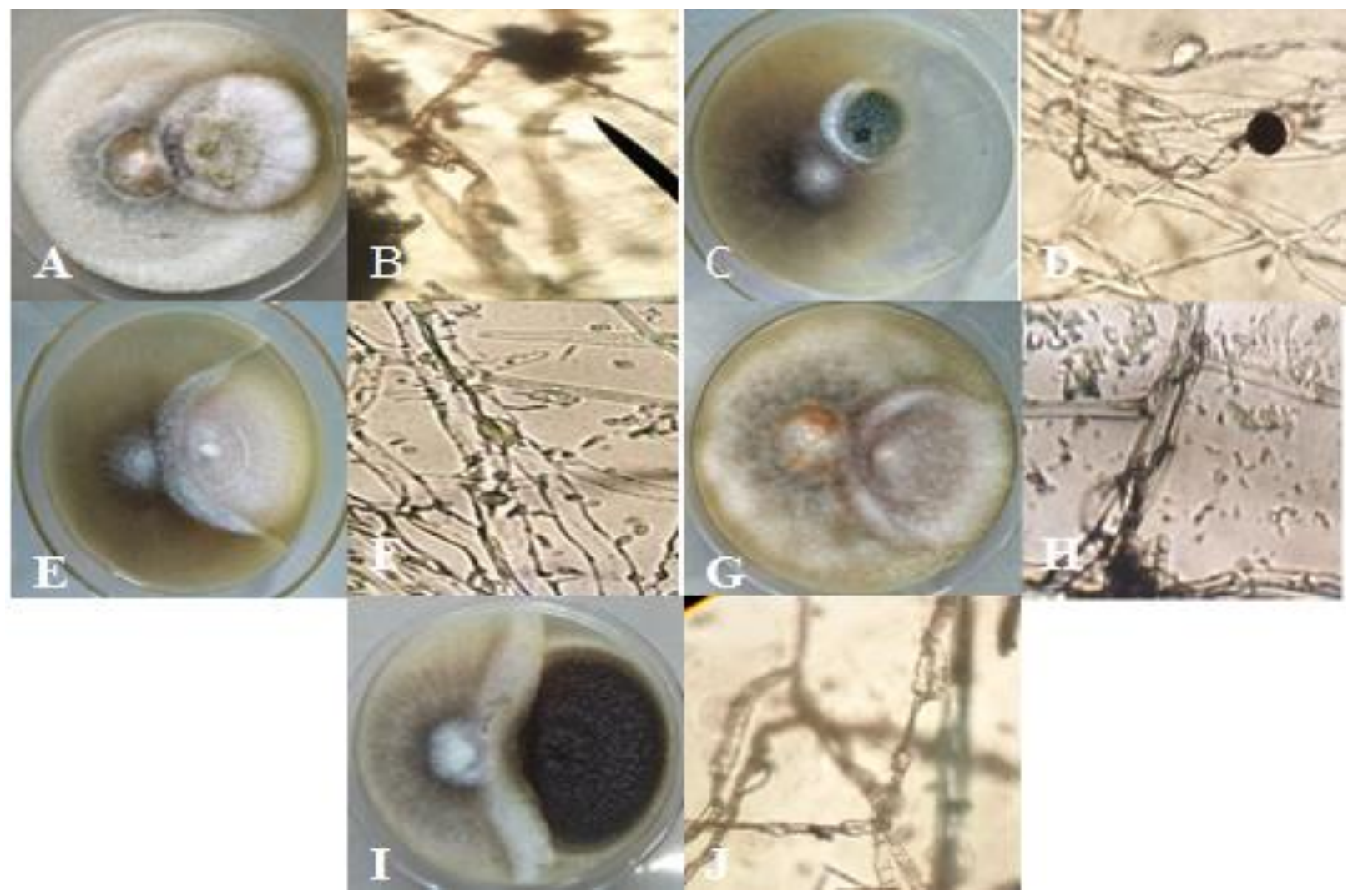

Fig. 4 - Antagonistic interaction represented by; A M. velutinosus (left) and A. flavus (right). B hyphal denaturation and lysed cells of A. flavus (400x). C M. velutinosus (left) and A. fumigatus 
(right). D hyphal denaturation and lysed cells of A. fumigatus (400x). E M. velutinosus (left) and $F$. solani (right). $\mathrm{F}$ hyphal penetration of $M$. velutinosus to $F$. solani (400x). G M. velutinosus (left) and $F$. oxysporum (right). $\mathrm{H}$ hyphal penetration of $M$. velutinosus to $F$. oxysporum (400x). I $M$. velutinosus (left) and A. niger (right). J hyphal denaturation and lysed cells of M. velutinosus (400x).

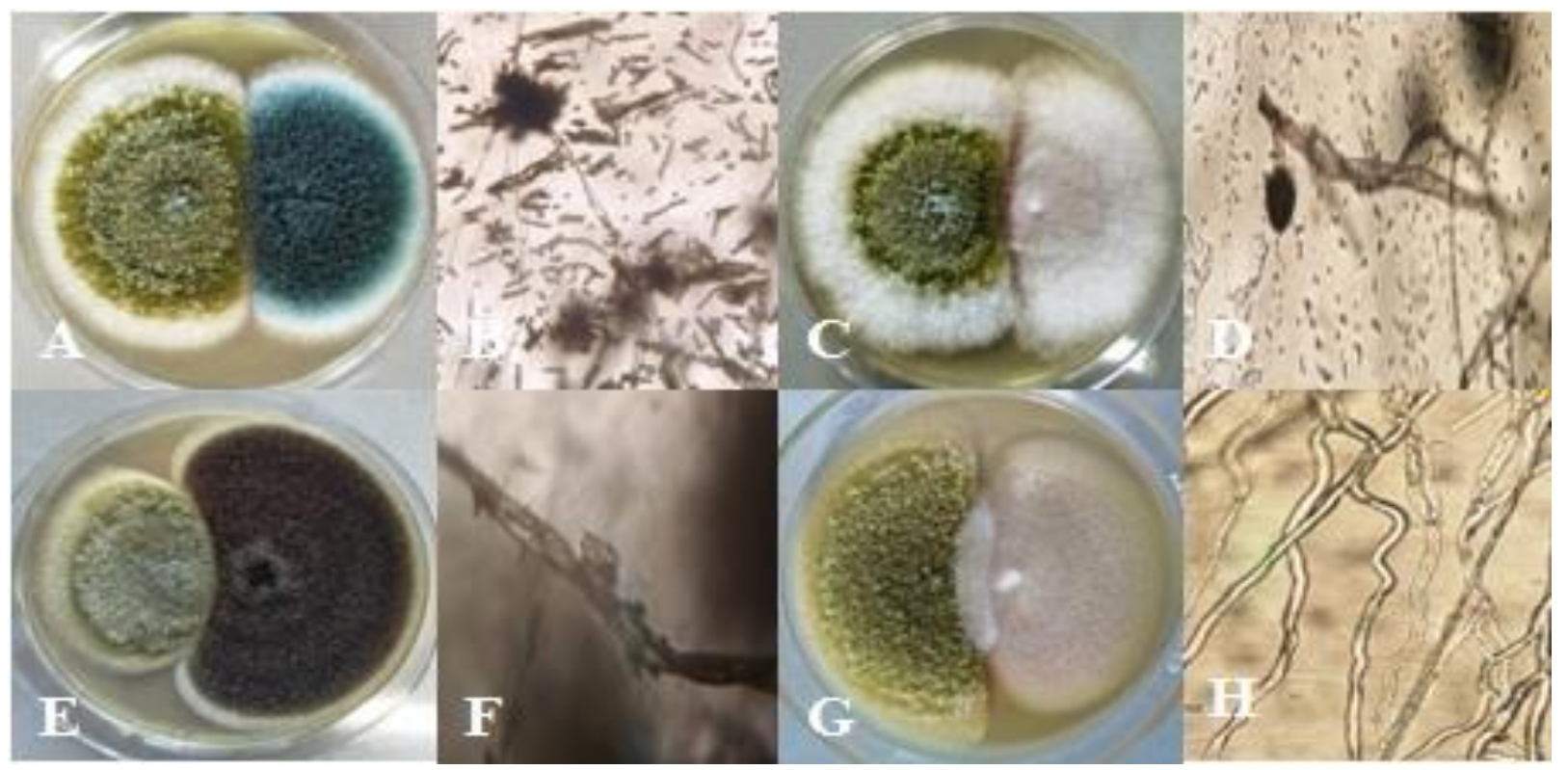

Fig. 5 - Antagonistic interaction represented by; A A. flavus (left) and A. fumigatus (left). B lysed cells of conidiophores of A. flavus (400x). C A. flavus (left) and $F$. oxysporum (right). D hyphal coiling of $F$. oxysporum leading to hyphal denaturation of $A$. flavus (400x). E A. flavus (left) and A. niger (right). F hyphal denaturation of $A$. flavus (400x). G A. flavus (left) and $F$. solani (right). $\mathrm{H}$ hyphal denaturation and lysed cells of $F$. solani (400x).

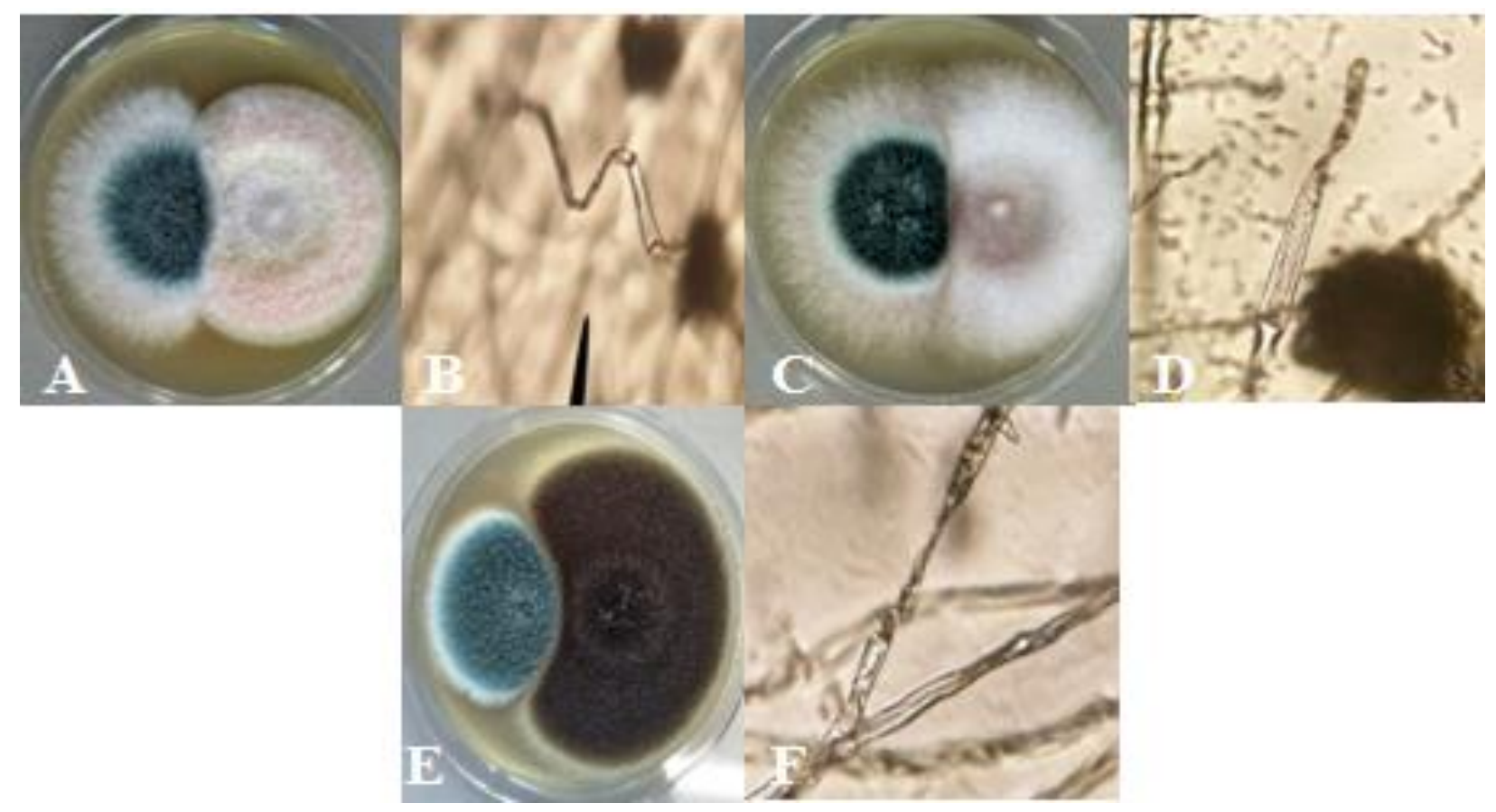

Fig. 6 - Antagonistic interaction represented by; A A. fumigatus (left) and $F$. solani (right). B hyphal denaturation of $A$. fumigatus (400x). CA. fumigatus (left) and $F$. oxysporum (right). 
D lysed cells of A. fumigatus (400x). EA. fumigatus (left) and A. niger (right). F lysed cells of $A$. fumigatus (400x).

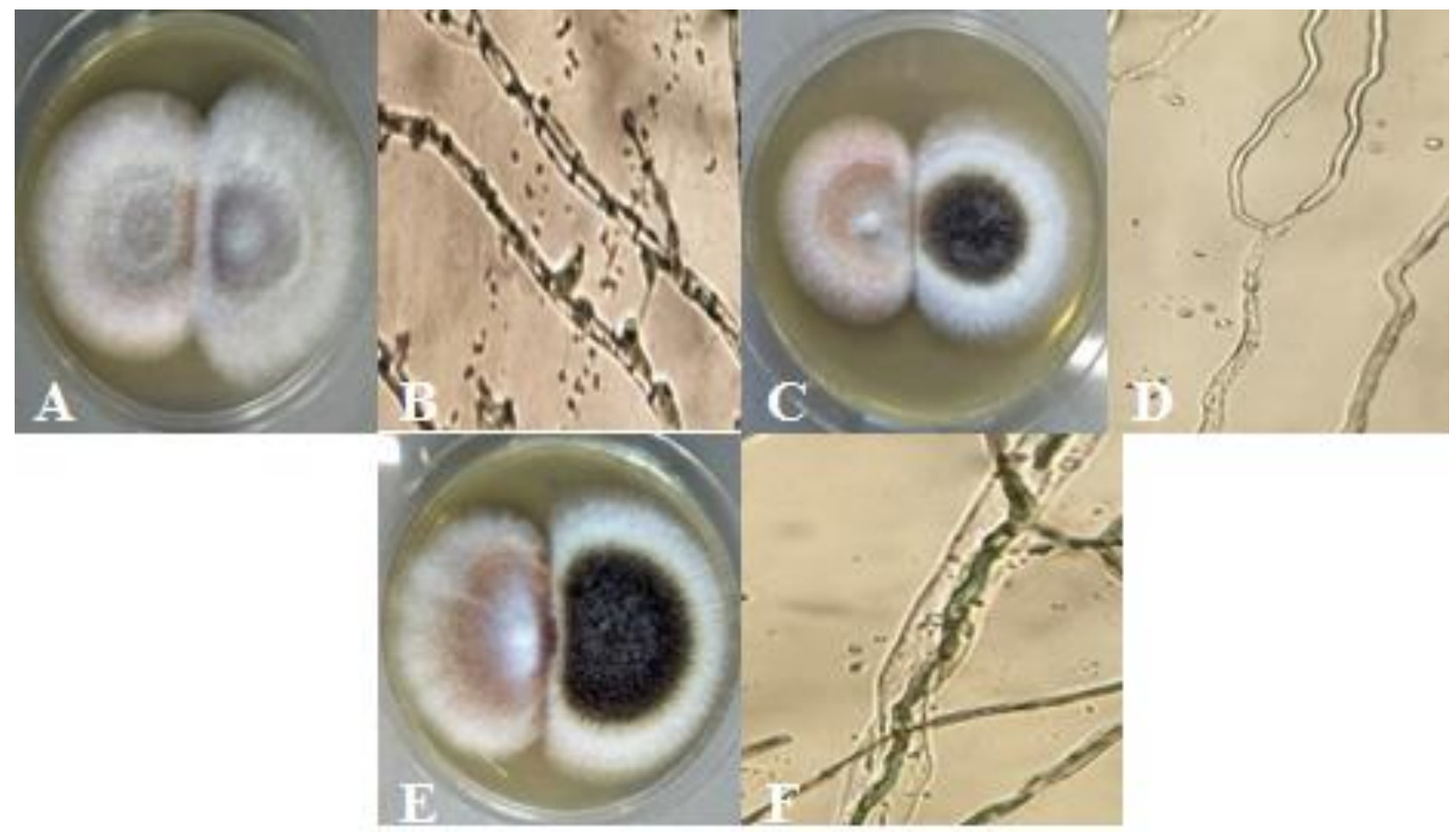

Fig. 7 - Antagonistic interaction represented by; A $F$. solani (left) and $F$. oxysporum (right). B hyphal penetration of $F$. oxysporum to $F$. solani (400x). C F. solani (left) and A. niger (right). D hyphal denaturation and lysed cell of $F$. solani (400x). E F. oxysporum (right) and A. niger (left). F hyphal penetration of $F$. oxysporum to A. niger (400x).

\section{Discussion}

Observed characteristics of infected potato with dry rot disease are similar to the study of Wharton (2015). In addition, wounds caused by unavoidable process of harvesting potato allowed the manifestation of fungal organisms that later on led to dry rot disease (Wharton et al. 2007). The present study has isolated two species of Fusarium, $F$. solani and $F$. oxysporum in which based on the study conducted by Stefanczyk et al. (2016), Fusarium species have been associated with potato dry rot. Such, $F$. sambucinum, $F$. solani and $F$. oxysporum are the most frequent and devastating species. In addition, three species of Aspergillus namely: A. flavus, A. fumigatus and A. niger were also isolated. According to the study of Ibrahim \& Tambuwal (2015), A. niger, and A. fumigatus were both pathogenic causing rotting of tomato fruit. Meanwhile, A. flavus was previously isolated from Dioscorea spp. rot (Okigbo \& Ogbonnaya 2006). Moreover, M. velutinosus is one of the most frequent fungal endophyte identified from the rotted root samples of D. arayalpathra (Premalatha et al. 2014). Fungal epiphytes are found on the surface of the plants. Also, many of them are obligate parasites which penetrated the host plant and prevent the uptake of the nutrients as cited by Hongsanan et al. (2016). These isolated fungal species are confirmed through BLAST analysis. In which based on the previous study of Nagano et al. (2008) the use of ITS primer for fungal identification shows accurate and reliable result. Furthermore, ITS primer is the standard marker for fungal DNA barcoding (Bellemain et al. 2010) and is generally used for the assessment and characterization of fungal communities from environmental samples (George et al. 2019).

The interaction study revealed antagonism between all identified fungi. Hyphal denaturation, hyphal coiling, hyphal penetration and lysed cells were the observed antagonistic interaction of hypha. In which, $M$. velutinosus showed the ability to penetrate the host hyphae of the $F$. solani and $F$. oxysporum which are considered as causative agents of potato dry rot. In microbial communities, 
there are different relationships and interactions characterized by mutualism to antagonism and parasitism (Duffy et al. 2003). These interactions happen when nutrients and space are limited (Arya \& Perello 2010). Fungi that affects the other by harming them by means of suppressing the growth of other or killing them is mycoparasitism or hyperparasites (Jeffries 1995, Kumar \& Gouda 2018). Its behavior which was observed in previous studies includes hyphal penetration, hyphal coiling, hyphal branching, hyphal denaturation, cell lysis, spore production, and barrier formation (Dubey \& Dwivedi 1986, El-Debaiky 2017). As a result of these interactions, the host hyphae were vacuolated, shrank, collapsed, and disintegrated. Moreover, at the interface region of colonies, certain fungi were observed having irregular branched hyphae, cracked hyphae, ruptured cell wall, and dead cells at the center of antagonism line (Chet et al. 1981, Xing et al. 2005). The ability of mycoparasites to penetrate the host cell after coiling can lead to cell lysis because of the enzymatic interaction. Wherein, certain fungus penetrates internally and uses direct enzymatic lysis of hyphal cells. Hyphal coiling incorporated by means of hock between the hyphae and lysed cells can lead to fusion. In addition, hyphal cell wall lysis leads to penetration of the hyphae for obtaining nourishment to the host by means of haustoria (Dubey \& Dwivede 1986, El-Debaiky 2017). However, certain host fungi counter attack by forming resting bodies. Also, host hypha accumulates cytoplasm to stop the infiltration of antagonist inside the cell. These host defense act as a barrier and survival measures against destruction in adverse condition and the over expression of pyridoxal reductase is a result of stress condition of a certain host fungi (Dubey \& Dwivede 1986, Chamoun \& Jabaji 2011, El-Debaiky 2017). According to the studies of Barnette (1963) and El-Debaiky (2017), the degree of damage by the parasites to the host cells depends to the resistance of host species. These studies show that certain parasites have direct contact to the host because of the absence of diffusible antibiotics which caused severe damage. In addition, some antagonist can produce spore inside the host hypha depending to the nutrition from the host fungi. Furthermore, according to Verma et al. (2007), there are several modes of actions that mycoparasitism exhibited which includes competition in space and nutrient, production of antibiosis and plant defense system induction. One evidence of this mode was observed by Waing et al. (2015) in which, the presence of zone of inhibition was observed when the two fungi are paired which indicates the production of antibiotics.

Emerging fungal diseases in various agricultural crops due to rapid growth of new pathogens that are fungicide resistant posed a significant threat in agricultural productivity and risk to global food security (Fones et al. 2020). An example of which is the fungal disease known as Septoria tritici blotch (STB) that resulted to $€ 240$ million per year in yield losses in UK growers alone (Fones \& Gurr 2015). In order prevent loss due to fungal pathogens, fungicides were being applied. However, commercially available fungicides are expensive and became an added burden to farmers at the same time it is not environmental friendly (Gomathi \& Ambikapathy 2011, Globe Newswire 2018). Thus, public concerns arise due to the hazardous effect of these harmful chemicals in the field of agriculture. Therefore, biocontrol microorganism has been stimulated as a substitute and answers for the pest control (Raaijmakers et al. 2002) and biocontrol pf pathogens. Several mycoparasites which belongs to the filamentous fungal genus were the best candidates for bio control agent against fungal pathogens (Kredics et al. 2003). Species exhibited extracellular enzyme such as polygalaturonase, amylase, protease and lipase which enable them to absorb nutrients (Gibb \&Strohl 1987, Alvez et al. 2002). Thus, certain biocontrol agents not only function as pest control but can also enhance the uptake of nutrients in plants, slow down the occurrence of abiotic stresses and some can reduce physiological stresses (Shoresh et al. 2010).

\section{References}

Adebola MO, Amadi JOE. 2010 -Screening three Aspergillus species for antagonistic activities against the cocoa black pod organisms (Phytophthora palmivora). Agriculture and Biology Journal of North 1, 362-365. 
Alvez MH, Takaki GM, Porto AL, Milanez AI. 2002 - Screening of Mucor spp. for the production of amylase, lipase, polygalacturonase and protease. Brazillian Journal of Microbiology 33.

Arya AO, Parello AE. 2010 - Management of fungal plant pathogens. Center for Agriculture and Bioscience International Publishing, 403.

Barnette HL. 1963 -The nature of mycoparasitism by fungi. Annual Review Microbiology 17,114.

Bellemain E, Carlsen T, Brochmann C, Coissac E, Taberlet P, Kauserud H. 2010 - ITS as an environmental DNA barcode for fungi: an in silico approach reveals potential PCR biases. BMC Microbiology 10, 189.

Brimmer TA, Boland GJ. 2003 -A review of the non-target effects of fungi used to biologically control plant diseases. Agriculture, Ecosytem and Environment 100, 3-16.

Camire ME, Kubow S, Donnely D. 2009 -Potatoes and human health. Critical Reviews in Food Science and Nutrition 49, 823-40.

Chamoun R, Jabaji S. 2011 -Expression of genes of Rhizoctonia solani and the biocontrol Stachybotrys elegans during mycoparasitism of hyphae and sclerotia. Mycologia Journal 103, 483-493.

Chet I, Harman GE, Baker R. 1981 - Trichoderma hamatum: its hyphal interactions with Rhizoctonia solani and Pythium spp. Microbial Ecology 7, 29-38.

Cullen DW, Toth IK, Pitkin Y, Boonham N et al. 2005 - Use of quantitative molecular diagnostic assays to investigates Fusarium dry rot in potato stocks and soil. Phytopathology 95, $1462-1471$.

Dix NJ, Webster J. 1995 -Fungal ecology. Japanese Journal of Ecology 45,332-333.

Dubey RC, Dwivedi RS. 1986 -Destructive mycoparasitic behaviour of Fusarium solani (Mart.) App. and Woll. against Mucor spinosus Van Tieghem. Microbios Letter 32, 123-127.

Duffy B, Schouten A, Raaijmakers JM. 2003 -Pathogens cell defense: mechanisms to counteract microbial antagonisms. Annual Review Phytopathology 41, 501-538.

El-Debaiky SA. 2017 -Antagonistic studies and hyphal interaction of the new antagonist Aspergillus piperis against some phytopathogenic fungi in-vitro in comparison with Trichoderma harzianum. Microbial Pathogenesis 113, 135-143.

Fakhrunnisa M, Hashmi H, Ghaffar A. 2006 -In vitro interaction of Fusarium spp. with other fungi. Parkish Journal of Botany 38, 1317-1322.

Fernald M. 1970 - Gray's manual of botany: a hand book of the flowering plants and ferns of the central and northeast United States and adjacent Canada $8^{\text {th }}$ edition. American Book Company, New York, 1251.

Fones HN, Bebber DP, Chaloner TM, Kay WT et al. 2020-Threats to global food security from emerging fungal and oomycete crop pathogens. Nature Food 1, 332-342.

Fones H,Gurr S. 2015-The impact of Septoria tritici blotch disease on wheat: an EU perspective. Fungal Genetics Biology79, 3-7.

George PBL, Creer S, Griffiths RI, Emmett BA, Robinson DA, Jones DL. 2019 - Primer and data base choice affect fungal function but not biological diversity findings in a national soil survey. Frontiers in Environmental Science 7, 173.

Gibb GD, Strohl WR. 1987 - Physiological regulation of protease activity in Streptomyces peucetius. Canadian Journal of Microbiology 34, 187-190.

Globe Newswire. 2018-Global fungicides market research report. https://www.globenewswire.com/en/news-release/2018/01/17/1295610/0/en/GlobalFungicides-Market-Noticeable-Shift-from-Inorganic-to-Organic-Fungicides-to-PropelGrowth-in-Market-finds-TMR.html (Accessed on May 15, 2021).

Gomathi S, Ambikapathy V. 2011 - Antagonistic activity of fungi against Pythium debayanum (Hesse) isolated from chili field soil. Advances in Applied Science Research 2, 291-297.

Hay WT, Fanta GF, Rich JO, Schisler DA, Selling GW. 2019 - Antifungal activity of a fatty ammonium chloride amylose inclusion complex against Fusarium sambucinum; control of dry rot on multiple potato varieties. American Journal of Potato Research 96, 79-85. 
Hongsanan S, Sanchez S, Crous PW, Ariyawansa HA et al. 2016 -The evolution of fungal epiphytes. Mycosphere 7, 1690-1712.

IbrahimM, Tambuwal NI. 2015 -Mycoflora associated with post-harvest rots of tomato (Solanum lycopersiconL.) fruits in Sokoto, Northwestern, Nigeria. Journal of Zoological and Bioscience 2(2), 42-46.

Jayasiri SC, Hyde KD, Ariyawansa HA, Bhat J et al. 2015 - The Faces of Fungi database: fungal names linked with morphology, phylogeny and human impacts. Fungal Diversity 74(1):318. Doi 10.1007/s13225-015-0351-8

Jeffries P. 1995 -Biology and ecolgy of mycoparasitism. Canadian Journal of Botany 73, 12841290.

Kredics L, Zsuzsanna A, Manczinger L, Szekeres A et al. 2003 - Influence of environmental parameters on Trichoderma strains with biocontrol potential. Food Technology Biotechnology 41, 37-42.

Kumar D, Gouda A. 2018 - Evaluation of mycoparasitic efficacy of nematode-trapping fungi against Rhizoctonia solani inciting sheath blight disease in rice (Oryza sativa L.). Science Direct 122, 31-40.

Li KL. 1992 - The dry rot of potato in Hohhot. Acta Science National University Intramongolica23, 429-433.

Matroudi S, Zamani MR, Motallebi M. 2009 - Antagonistic effect of three species of Trichoderma sp. on Sclerotinia sclerotiorum, the causal agent of canola stem rot. Egyptian Journal of Biology 11, 37-44.

Nagano Y, Elborn JS, Millar BC, Goldsmith CE, Rendall J, Moore JE. 2008 - Development of novel PCR assay for the identification of the black yeast, Exophiala (Wangiella) dermatitidis from adult patients with cystic fibrosis (CF). Journal of Cystic Fibrosis 7, 576-580.

Okigbo RN, Ogbonnoya UO. 2006 -Antifungal effects of two tropical plant leaf extracts (Ocimum gratissimum and Aframomum melegueta) on postharvest yam (Dioscorea spp.) rot. African Journal of Biotechnology 5, 721-731.

Peng XW, Zhu JH. 2008 - Variety and distribution of potato fungi disease in Herbei Province. China Potato Journal 22, 31-33.

Premalatha K, Gokul S, Amit K, Priyanka M et al. 2014 -Molecular profiling of fungal assemblages in the healthy and infected roots of Decalepis arayalpathra (J. Joseph \& V. Chandras) Venter, an endemic and endangered ethnomedicinal plant from Western Ghats, India. Annals of Microbiology 65.

Raaijmakers J, Vlami M, De Souza J. 2002 - Antibiotic production by bacterial biocontrol agents. Kluwer Academic Publishers 81, 537-547.

Shoresh M, Harman G, Mastouri F. 2010 -Induced systematic resistance and plant responses to fungal biocontrol agents. Annual Review of Phytopathology 48, 21-43.

Spooner DM, Knapp S. 2013 - Solanum stipuloideum Rusby, the correct name for Solanum circaeifolium Bitter. American Journal Potato Research 90, 301-305.

Stefanczyk E, Sobkowiak SM, Brylinska M, Sliwka J. 2016 -Diversity of Fusarium spp. associated with dry rot of potato tubers in Poland. Europe Journal Plant Pathology 145, 871-884

Verma M, Brar SK, Tyagi RD, Surampalli RY, Valero JR. 2007 -Antagonistic fungi, Trichoderma spp.: panoply of biological control. Biochemical Engineering Journal 37, 1-20.

Waing KGD, Abella EA, Kalaw SP, Waing FP, Galvez CT. 2015 -Antagonistic interaction among different species of leaf litter fungi of Central Luzon State University. Plant Pathology \& Quarantine 52, 122-130.

Wharton P. 2015 - Potato disease Fusarium dry rot (E2992). Department of Plant Pathology, Michigan State University. https://www.canr.msu.edu/resources/ potato diseases fusarium dry rot e2992 (Accessed on November 15, 2018).

Wharton P, Hammerschmidt R, Kirk W. 2007 -Department of Plant Pathology, Michigan State University. https://www.canr.msu.edu/uploads/files/fusarium-dry-rotbulletin.pdf (Accessed on November 15, 2018). 
Xing KY, Guo SX, Lee MW. 2005 -Morphological characteristics of hyphal interaction between Grifola umbellate and its companion fungus. Mycobiology Journal 33, 1-6.

Ye Q, Wang, GC. 1994 - On Fusarium dry rot of potato in Zhejiang. Acta Phytopathology 5(14). 